\title{
LIPID LEVELS IN ACROMEGALY
}

Ifigenia Kostoglou-Athanassiou, Anastasjos Gkountouvas, Ioannis Keramidas, Eleni Xanthakou, Fotini Chatjimarkou, Philippos Kaldrymidis

Department of Endocrinology, Red Cross Hospital, Athens, Greece

Endocrinologist

Department of Endocrinology, Metaxa Hospital, Pireaus, Greece 


\section{Introduction}

- Acromegaly is known to be associated with increased cardiovascular risk

- Additionally, acromegaly is known to be associated with disordered carbohydrate metabolism

- Lipid levels in acromegaly have not been extensively studied 


\section{Aim}

- The aim was to study lipid levels in acromegaly 


\section{Methods}

- In 32 patients with newly diagnosed acromegaly lipid levels were studied

- In particular total cholesterol, HDL cholesterol, LDL cholesterol and triglyceride levels were measured

- All patients had a pituitary adenoma

- All of them had increased IgF1 levels

- The measurements were also performed in 32 control subjects matched for age and sex 


\section{Results}

- Total cholesterol was $220.59 \pm 8.24 \mathrm{mg} / \mathrm{dl}$ (mean $\pm S E M$ ) in patients with acromegaly as opposed to $198,55 \pm 4.85 \mathrm{mg} / \mathrm{dl}$ in the control subjects ( $p<0.001$, Student's t test)

- HDL cholesterol levels were $52.96 \pm 2.89 \mathrm{mg} / \mathrm{dl}$ in patients with acromegaly as opposed to $58.44 \pm 3.62 \mathrm{mg} / \mathrm{dl}$ in the control group $(p<0.001)$

- LDL cholesterol was $151.70 \pm 13.77 \mathrm{mg} / \mathrm{dl}$ in the acromegalic patients as opposed to $114.06 \pm 5.31$ $\mathrm{mg} / \mathrm{dl}$ in the control group $(p<0.001)$ 


\section{Results}

- Triglyceride levels were 140.34+14.79 $\mathrm{mg} / \mathrm{dl}$ in patients with acromegaly as opposed to $133.50 \pm 14.27 \mathrm{mg} / \mathrm{dl}$ in the control group $(p<0.001)$

u Thus, total cholesterol, LDL cholesterol and triglyceride levels were increased in patients with acromegaly as opposed to the control group, while HDL cholesterol was decreased 


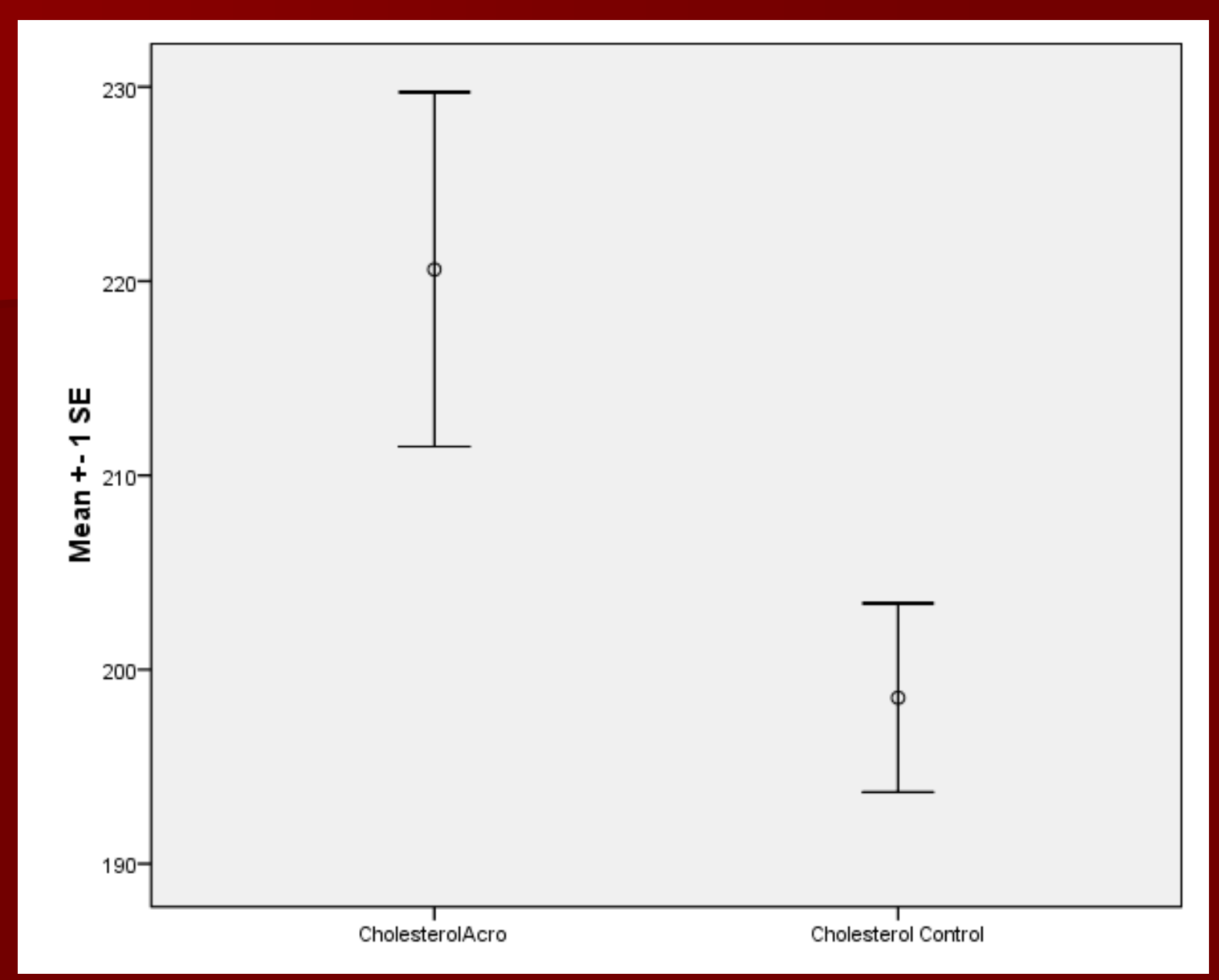

Total cholesterol in patients with acromegaly and controls 


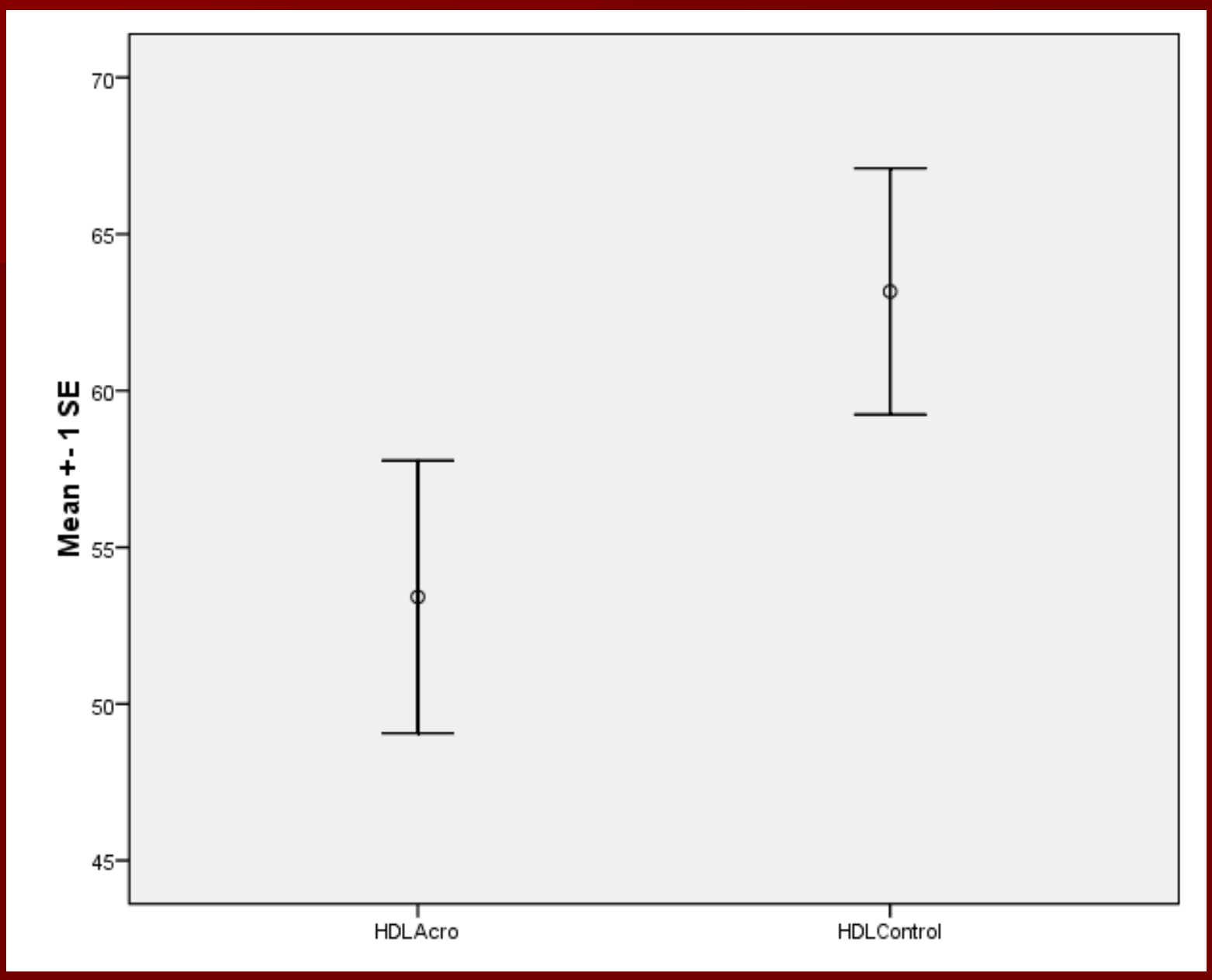

HDL cholesterol in patients with acromegaly and controls 


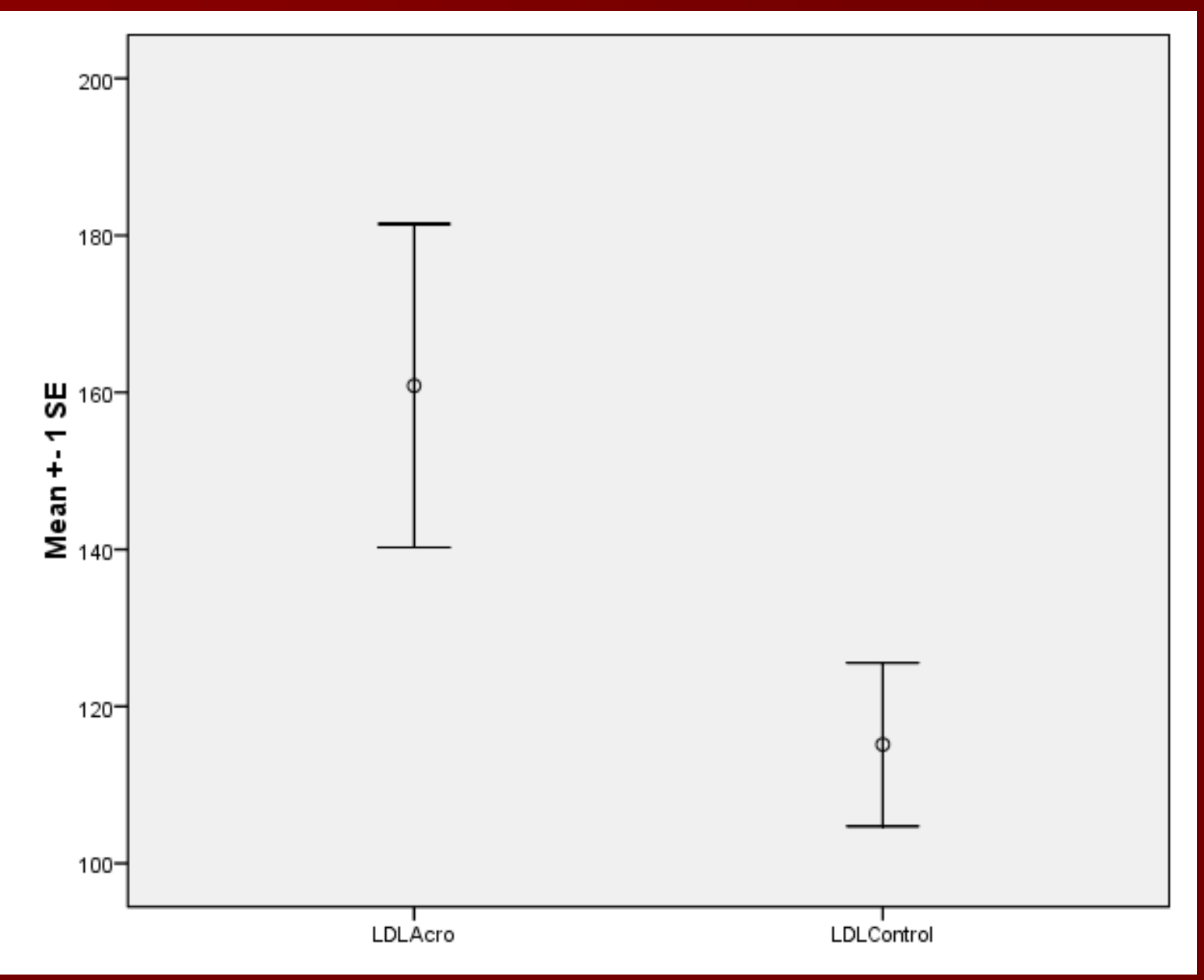

LDL cholesterol in patients with acromegaly and controls 


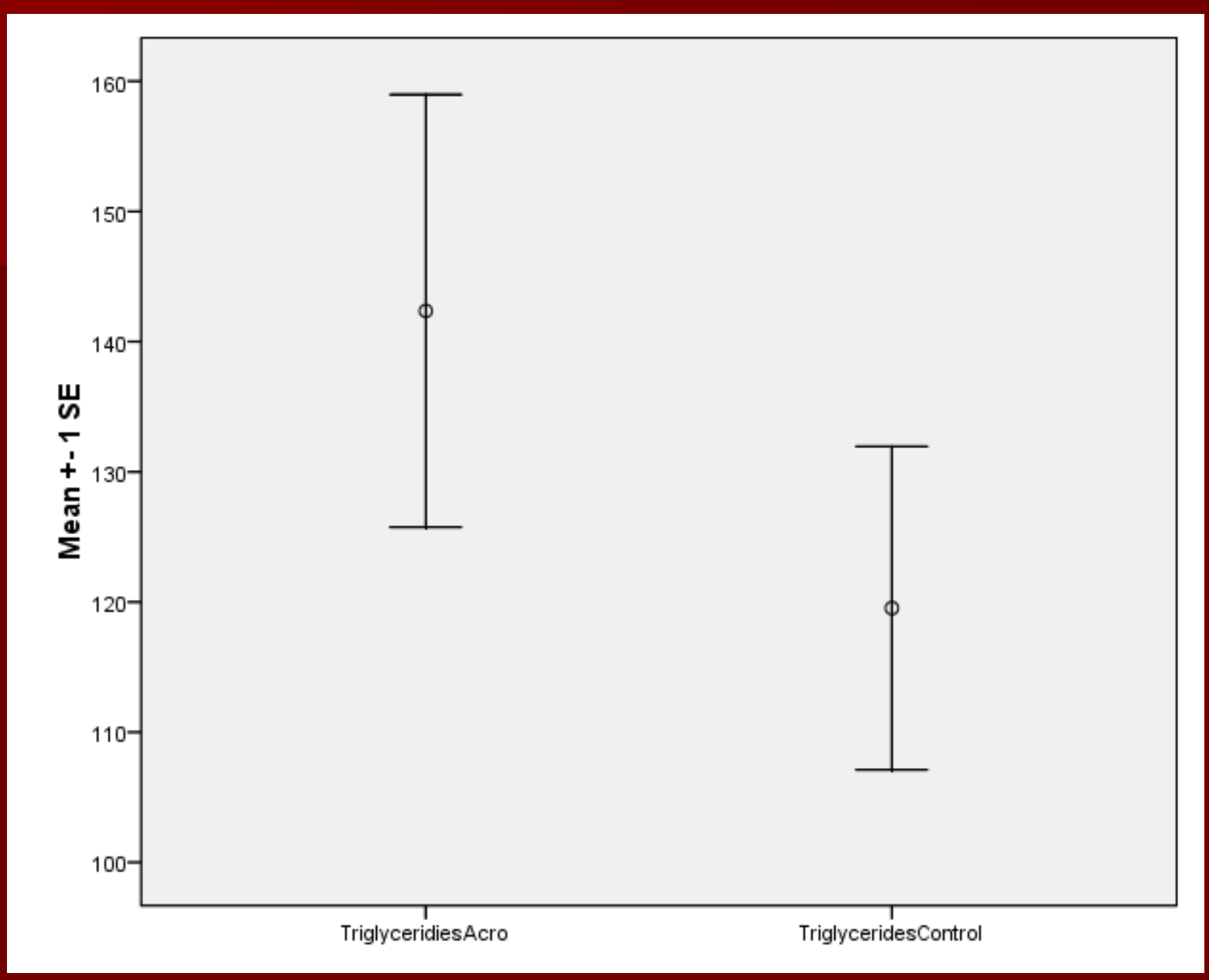

Triglyceride levels in patients with acromegaly and controls 


\section{Conclusions}

- It appears that acromegaly is associated with a proatherogenic lipid proffle, which may contribute to the increased cardiovascular risk associated with the disease 